www.uoc.edu/idp

\title{
La modernización y transformación digital de la Administración de Justicia: el papel del Consejo General del Poder Judicial
}

\author{
Juan Ignacio Cerdá Meseguer \\ Universidad de Murcia
}

Fecha de presentación: marzo de 2020

Fecha de aceptación: julio de 2020

Fecha de publicación: octubre de 2020

\begin{abstract}
Resumen
Hace aproximadamente una década se inició una ambiciosa reforma en la Administración de Justicia que afectaba a todos los ámbitos de la misma: estructural, funcional, personal y tecnológico. A tal fin, se acometió la promulgación de las normas reguladoras de la Nueva Oficina Judicial (NOJ); se aprobaron las necesarias reformas legales para adaptar las distintas funciones y competencias del personal al servicio de la Administración de Justicia; se promulgó la Ley 18/2011, de 5 de julio, reguladora del uso de las tecnologías de la información y la comunicación en la Administración de Justicia (LUTICAJ); y, finalmente, se han impulsado importantes reformas en normas procesales con el fin de adaptarlas a un nuevo paradigma: la Justicia electrónica o e-Justicia, que se pretende más moderna, eficiente, eficaz y capaz de dar respuestas a los requerimientos que la sociedad demanda de este servicio público en el siglo xxı. Sin embargo, el resultado no ha sido, en muchos aspectos, el que se esperaba de tan relevante reforma. En este trabajo nos proponemos analizar las acciones del CGPJ, los indudables logros alcanzados, pero también los problemas pendientes de resolver y que impiden, en definitiva, la culminación de este proceso de modernización.
\end{abstract}

\section{Palabras clave}

e-Justicia, Administración de Justicia, modernización, transformación digital

\section{Tema}

Derecho Administrativo, Administración electrónica, Justicia electrónica 


\title{
The modernisation and digital transformation of the administration of justice: the role of the General Council of the Judiciary
}

\begin{abstract}
About a decade ago an ambitious reform in the administration of justice began that affected all its areas: structural, functional, personal and technological. To this end, the promulgation of the regulatory norms of the New Judicial Office (NJO) was undertaken; the necessary legal reforms were approved to adapt the different functions and competences of the personnel to the service of the administration of justice; Law 18/2011, of July 5, regulating the use of information and communication technologies in the administration of justice was promulgated; and, finally, important reforms in procedural norms have been promoted in order to adapt them to a new paradigm: electronic Justice or e-Justice, which aims to be more modern, efficient, effective and capable of responding to the requirements that society demands for this public service in the 21st century. However, the result has not been, in many respects, what was expected of such a relevant reform. In this work we will analyse the actions of CGPJ (General Council of the Judiciary), the undoubted achievements, but also the problems that are pending to be resolved and that ultimately prevent the culmination of this modernisation process.
\end{abstract}

\section{Keywords}

e-Justice, Administration of justice, modernisation, digital transformation.

\section{Topic}

Administrative law, electronic Administration, electronic justice.

\section{Introducción}

Administrar justicia es una de las más complejas funciones que actualmente desarrolla el Estado concebido como poder público, sobre todo desde un punto de vista técnico. La Administración de Justicia se presenta como la garante, en última instancia, de los derechos y libertades. Para cumplir con este cometido la Justicia debe ser capaz de dar respuesta a las demandas y necesidades de la sociedad con agilidad y eficiencia. En última instancia, su correcto funcionamiento es esencial en un Estado de derecho.
Históricamente la Administración de Justicia en España estaba residenciada en un modelo con una estructura arcaica, tecnológicamente muy limitada y lastrada por un endémico problema de este servicio público: la falta de jueces y magistrados, lo que se concretaba en la incapacidad de dar respuesta a la alta litigiosidad en tiempos razonables. Consecuentemente, la percepción social de este servicio público era en general negativa, reflejo de una Administración obsoleta que era, además, la peor valorada', percepción que no se ha conseguido revertir. La Administración de Justicia sigue siendo demasiado lenta, adolece de agilidad para ofrecer respuestas eficaces, sigue siendo oscura, poco comprensible para los profanos en la

1. Un análisis de la imagen de la Justicia entre los años 1985 a 2015 puede verse en CERDÁ MESEGUER, J. I. (2018). El uso de medios electrónicos en la Administración de Justicia. Del expediente en papel al expediente electrónico. Valencia: Tirant Lo Blanch, págs. 87-97. 
materia y alejada, en muchas ocasiones, de la realidad que vive la sociedad a quien tiene la obligación de servir². En este contexto, otro factor que resulta determinante cuando se trata de analizar la evolución y el estado actual de la Administración de Justicia es el retraso con el que se ha acometido su modernización e incorporación a la sociedad de la información, en particular para adaptar y utilizar las tecnologías de la información y la comunicación en el desarrollo de su actividad ${ }^{3}$. Este retraso se debe, además, a la fragmentación competencial que, unida a la falta de una efectiva coordinación entre las distintas Administraciones con competencias en la materia y el propio Consejo General del Poder Judicial (CGPJ), supone que la modernización estructural, funcional y tecnológica se produzca de manera desigual y termine por afectar al diseño y funcionamiento conjunto del sistema, en particular si tenemos en cuenta las exigencias de interoperabilidad que plantea la implantación de la tecnología.

De la misma forma, las inercias contrarias a una modernización radical por parte de muchos de los colectivos implicados -personal funcionario, jueces y magistrados, y profesionales- y del propio Ejecutivo -que puede ver en una Justicia ágil, moderna y dotada de medios un elemento de control de sus actuaciones ${ }^{4}$ - suponen una limitación importante para que esos avances sean todo lo efectivos que se preveían. Por otra parte, no ha habido un auténtico impulso a la incorporación de las tecnologías de la información y la comunicación hasta hace pocos años, y es aún reciente la implantación de un sistema que pueda llegar a ser efectivo pero que, en nuestra opinión, se ha visto negativamente afectado por una deficiente previsión tanto por lo que se refiere a la formación como a los medios disponibles.
Así pues, la Administración de Justicia sigue pendiente de culminar la reforma iniciada para poder obtener los beneficios y ventajas que el uso de la tecnología puede reportar de inmediatez -por el ahorro en tiempo y la consiguiente agilización en la tramitación de expedientes- y de reducción de costes y necesidades de espacio, mejoras que se han podido apreciar desde hace años en otros ámbitos como el tributario o la Seguridad Social ${ }^{5}$.

Se trata en definitiva de poner los medios para «prestar servicios públicos de mejor calidad, reducir los tiempos de espera, mejorar la eficacia en el uso de los fondos públicos, aumentar la productividad y mejorar la transparencia y la rendición de cuentas» ${ }^{6}$. Todo ello sin que se retroceda en el respeto a los derechos de los ciudadanos y ciudadanas, quienes no deben ver mermadas sus garantías jurídicas ante la mayor eficacia que se presume de la innovación tecnológica ${ }^{7}$, uno de los pilares en los que se asienta el proceso de modernización.

\section{La reforma de la Administración de Justicia diez años después}

La reforma de la Oficina Judicial se inicia con un doble objetivo. Por una parte, su rediseño estructural, funcional, espacial y de personal y, por otra, la incorporación de la tecnología con el objetivo de optimizar la actividad del personal y los recursos. Una especial atención se ha prestado a la implantación del expediente judicial electrónico, con el que se pretendía reducir los tiempos de tramitación y la excesiva burocratización eliminando el uso del papel

2. En este sentido, CERDÁ MESEGUER, J. I. (2018), op. cit., pág. 22; y BUENO DE MATA, F. (2014). Prueba electrónica y Proceso 2.0. Valencia: Tirant Lo Blanch, pág. 23. También JIMÉNEZ GÓMEZ, C. E. (2014). «Desafíos de la modernización de la Justicia en tiempos del Gobierno Abierto». Revista Digital de Derecho Administrativo, núm. 12, págs. 225-239.

3. Véase DELGADO GARCÍA, A. M. a; OLIVER CUELLO, R. (2007). «Administración de Justicia y tec-nologías de la información y la comunicación: aspectos jurídicos». Revista Aranzadi de Derecho y Nuevas Tecnologías, núm. 13, pág. 1. También JIMÉNEZ GÓMEZ, C. E. (2014), op. cit., pág. 226.

4. SUÁREZ-QUIÑONES Y FERNÁNDEZ, J. C. (2010). «Administración de Justicia y Nuevas Tecnologías: presente y futuro». Diario La Ley, núm. 7.421. Véase también ORTUÑO MUÑOZ, P. (2011). «Del arancel al expediente electrónico (Notas históricas sobre el modelo de oficina judicial español)». Revista Jurídica Fundación Mariano Ruiz-Funes, núm. 45, pág. 105.

5. GAMERO CASADO, E.; MARTÍNEZ GUTIÉRREZ, R. (2010). «El Derecho Administrativo ante la Era de la Información». En: GAMERO CASADO, E.; VALERO TORRIJOS, J. (coords.). La Ley de Administración Electrónica. Comentario sistemático a la Ley 11/2007, de 22 de junio, de Acceso Electrónico de los Ciudadanos a los Servicios Públicos. Navarra: Aranzadi-Thomson-Reuters, págs. 64 a 68.

6. DELGADO GARCÍA, A. M. ${ }^{a}$; OLIVER CUELLO, R. (2006). Las tecnologías de la información y la comunicación en la Administración de Justicia. Oñati (Bilbao): Instituto Vasco de Administración Pública, pág. 10.

7. VALERO TORRIJOS, J. (2013). Derecho, Innovación y Administración Electrónica. Sevilla: Derecho Global, pág. 18. 
en todos sus trámites, en búsqueda de una mayor agilidad y eficacia que, en definitiva, supondría también una reducción de costes $^{8}$.

\subsection{El punto de partida}

Ha sido fundamentalmente en los últimos diez años cuando ha tenido lugar la aprobación de diversas normas jurídicas con las que se ha pretendido modificar el funcionamiento de la Administración de Justicia?.

En el plano estructural, las modificaciones legales operadas en los artículos 435 y sigs. de la Ley Orgánica 6/1985, de 1 de julio, del Poder Judicial (LOPJ) han tratado de incorporar un nuevo modelo de oficina judicial (NOJ). Hasta entonces, su estructura se basaba en un «modelo diseñado en el siglo xix para una sociedad eminentemente rural y con un muy diferente sistema de comunicaciones $\rangle^{10}$, en el que cada juzgado y tribunal funcionaba de forma independiente, diseño que resultaba poco operativo y que algún sector de la doctrina ha calificado como «islas»"1". La NOJ pasará a estar integrada por dos unidades: Ios Servicios Comunes Procesales (SCP) y las Unidades Procesales de Apoyo Directo (UPAD)12. Esta nueva estructura está diseñada para una Administración de Justicia totalmente informatizada en la que el expediente judicial electrónico es el elemento fundamental de trabajo. En este contexto incipiente se producen las primeras implantaciones a modo de prueba y como experiencia piloto del modelo de NOJ en el año 2010, únicamente en algunas comunidades autónomas, en determinadas ciudades, y solo inicialmente en la jurisdicción social y civili'.
En el plano tecnológico se diseña la plataforma LexNET, se promulga la Ley 18/2011, de 5 de julio, reguladora del uso de las tecnologías de la información y la comunicación en la Administración de Justicia (LUTICAJ), que regula la incorporación de las TIC a la Administración de Justicia, y se procede a la progresiva implantación de los tres elementos clave: la NOJ, LexNET, regulado hoy por el Real Decreto 1065/2015, y el expediente judicial electrónico, cuya regulación básica se encuentra en la mencionada LUTICAJ. Asimismo, se acometen diversas reformas en leyes procesales para adaptar los procesos al nuevo expediente judicial electrónico. Básicamente, su regulación más detallada se encuentra en la Ley de Enjuiciamiento Civil como normativa procesal de referencia. En particular es necesario destacar la reforma operada por la Ley 42/2015, de 5 de octubre, en la que se estableció la obligación de utilizar medios electrónicos -y en concreto el sistema LexNET- en un intento de que la Administración de Justicia abandonara el soporte papel tanto en la gestión documental como en las presentaciones de escritos, notificaciones y comunicaciones. Sin embargo, dicha implantación fue a nuestro juicio precipitada, pues ni la Administración de Justicia estaba preparada tecnológicamente ni se apostó decididamente por la formación del personal y de los diversos colectivos profesionales implicados. Además, las carencias en cuanto a falta de interoperabilidad entre los distintos sistemas de gestión procesal, el retraso en la dotación a jueces y magistrados de la firma electrónica, la falta de cumplimiento de los requerimientos establecidos en el Esquema Nacional de Seguridad y, en definitiva, la ausencia de actuaciones coordinadas entre Administraciones han complicado la plena implantación del expediente judicial electrónico.

8. En este sentido, DELGADO GARCÍA, A. M.a; OLIVER CUELLO, R. (2006), op. cit., páq. 94.

9. Al respecto, PÉREZ-LUÑO ROBLEDO, E. C. (2019). «La informatización de la Administración de Justicia en España». En: CONDE FUENTES, J.; SERRANO HOYO, G. (dir.). La Justicia Digital en España y la Unión Europea: situación actual y perspectivas de futuro. Barcelona: Atelier, págs. 51 y 52.

10. 1PARRA GARCÍA, J. I. (2019). «La Oficina Judicial en España: un balance de diez años». Actividad formativa del curso «Estatuto orgánico LAJ» (8. ${ }^{a}$ ed.). Madrid: Centro de Estudios Jurídicos, 25 y 26 de noviembre de 2019.

11. ARNAIZ SERRANO, A.; TOMÁS PORTER, J. J. (2010). «La nueva oficina judicial y el nuevo modelo procesal: un estudio sobre la organización y funciones en la oficina judicial y los procesos judiciales tras la reforma de la legislación procesal operada por la Ley 13/2009». Revista jurídica de la Comunidad Valenciana: jurisprudencia seleccionada de la Comunidad Valenciana, núm. 33, págs. 69-93. También JIMÉNEZ ASENSIO, R. (2010). «El encaje constitucional de la NOJ». Ponencia presentada en el curso «La Nueva Oficina Judicial». Madrid: CENDOJ. Así como CERRILLO MARTíNEZ, A. (2010). «Cooperación entre Administraciones públicas para el impulso de la administración electrónica». En: GAMERO CASADO, E.; VALERO TORRIJOS, J. La Ley de Administración Electrónica. Comentarios a la Ley 11/2007, de 22 de junio, de Acceso Electrónico de los Ciudadanos a los Servicios Públicos. Navarra: Aranzadi-Thomson Reuters (Cizur Menor), pág. 780.

12. Sobre la nueva estructura de la NOJ, véase CLÈRIES I NERÍN, N. (2007). «Administración electrónica en el Área de Justicia». IDP. Revista de Internet, Derecho y Política, núm. 4, págs. 14 y 15. Monográfico e-Justicia [en línea] https://idp.uoc.edu/42/volume/0/issue/4/ [Fecha de consulta: 3 de septiembre].

13. Inicialmente se implanta en Zaragoza, Avilés, Palma de Mallorca, Santander, Ciudad Real, Burgos, Cáceres, Murcia, Logroño, Ceuta y Melilla. 
En el plano funcional, la transición de un modelo a otro se ha apoyado fundamentalmente en la figura del Letrado de la Administración de Justicia (LAJ), quien ha asumido no solo las tradicionales funciones de gestión, personal y fe pública judicial, sino que a estas se han sumado -no sin ciertas desavenencias y resistencias doctrinales ${ }^{14}$, funcio- $^{-}$ nes decisorias en determinadas fases del procedimiento e incluso la asunción total de la facultad de decidir en determinados tipos de procedimiento ${ }^{15}$. En puridad lo que se ha pretendido con la reforma es descargar al titular de órgano judicial de cualquier otra tarea que no sea la de juzgar y hacer ejecutar lo juzgado, reservando al LAJ y demás personal funcionario el resto de funciones ${ }^{16}$.

También en el ámbito espacial se preveían importantes cambios en el diseño de las nuevas oficinas judiciales. Frente al tradicional juzgado se pretende la implantación de grandes espacios comunes cuyo personal se adscribe a servicios comunes procesales especializados (de ordenación del procedimiento, de ejecución, de notificaciones y embargos, etc.), al frente de los cuales hay varios LAJ. Por otra parte, las UPAD están servidas por un reducido número de funcionarios que realizan las labores de asistencia al titular del órgano judicial, y que despachan los procedimientos que llegan desde los SCP para un determinado trámite que requiere decisión judicial, al frente de las cuales también se encuentra un LAJ que puede servir a uno o más órganos judiciales.

Así pues, este diseño institucional habría requerido una efectiva interconexión de los sistemas de información pues, como puede comprobarse, supone pasar de un modelo de gestión basado en cada órgano judicial a otro sustentado en la gestión común de espacios, herramientas y aplicaciones informáticas, lo cual supone en, definitiva, además de un cambio organizativo, un cambio cultural ${ }^{17}$, es decir, la aceptación plena por parte de todos los sectores implicados de que los avances, si bien lentos y costosos, se van a reflejar en mejoras en el servicio que presta la Justicia, en su gestión y en su eficiencia y eficacia. Sin embargo, las inercias contrarias existentes tanto a nivel político como a nivel de operadores jurídicos -tanto externos como internos- indican que falta por consolidarse ese cambio cultural y de mentalidad necesario para que se aborden las multiples tareas que aún quedan pendientes de realizar, como analizamos seguidamente.

\subsection{El estado actual de la Administración de Justicia}

De haberse seguido las previsiones normativas en cuanto a plazos y acciones programadas, en la actualidad la NOJ y el expediente judicial electrónico debieran estar plenamente implantados y funcionando con normalidad. No obstante, como hemos venido exponiendo, tales previsiones no solo no se han cumplido, sino que la dotación, situación e imagen de la Administración de Justicia sigue, prácticamente, en los mismos parámetros que al inicio de la reforma.

Estas acciones normativas referidas deben ir acompañadas de otras sinérgicas y proactivas de carácter económico y tecnológico. En este sentido, la insuficiente inversión presupuestaria, la fragmentación competencial unida a la ausencia de una efectiva coordinación, la falta de interoperabilidad entre los distintos sistemas de gestión procesal -también inicialmente con el sistema Fortuny de la Fiscalía General del Estado ${ }^{18}$-, han lastrado el proceso de modernización. Así, a nivel estructural, en la actualidad las

14. Acerca de esta disputa doctrinal véase SEOANE CHACARRÓN, J. (2011). «El Secretario Judicial ante la Ley 13/2009, de 3 de noviembre, de Reforma de la Legislación Procesal (civil y penal) para la implantación de la Nueva Oficina Judicial». Diario La Ley, núm. 7.561, pág. 1. También PARRA GARCÍA, J. L. (2010). «El año uno en la Oficina Judicial: nueva organización, nuevas formas de hacer Justicia». Derecho y Jueces, EL DERECHO, núm. 55, pág. 3. En sentido contrario, BANACLOCHE PALAO, J. (2009). «El proyecto de Nueva Oficina Judicial: ¿hacia un nuevo proceso administrativizado?». Diario La Ley, núm. 14.035. También en BANACLOCHE PALAO, J. (coord.) (2010). Guía Práctica de la Nueva Oficina Judicial. Madrid: Editorial LA LEY.

15. Ejemplos de lo afirmado son el Decreto de admisión a tramite de las demandas; que en los procesos de juras de cuentas el LAJ decide en todo momento; o que en las ejecuciones las primeras medidas contra el ejecutado las adopta el LAJ.

16. En este sentido, PARRA GARCÍA, J. L.; PASQUAL DEL RIQUELME HERRERO, M. (2009). «Oficina Judicial integrada o hacia una Justicia inteligente en España». Boletín del Ministerio de Justicia, año 63, núm. 2094, págs. 2.333-2.345; págs. 8-9 del trabajo.

17. Como ha señalado CLÈRIES I NERÍN, N. (2007). «Administración electrónica en el Área de Justicia», op. cit., pág. 13.

18. Para un análisis al respecto CERDÁ MESEGUER, J. I. (2018), op. cit., caps. I, II, III y VI. 
sedes de la NOJ con plena implantación están en las ciudades de Murcia, Cuenca, Ciudad Real, Cáceres, Badajoz, León, Burgos, Ceuta y Melilla ${ }^{19}$, sin que se haya implantado en el resto del Estado. En cuanto a la Oficina Fiscal solo se está implantando en el territorio donde ejerce sus competencias el Ministerio de Justicia y, dentro de este, está plenamente implantada en Murcia, Ceuta, Melilla, Cuenca y Cáceres ${ }^{20}$. Tan escaso índice de cumplimiento de las previsiones legales iniciales es indicativo de que, además de las causas indicadas, hay una importante falta de asunción y empatía con el nuevo modelo por parte de todos los sectores implicados.

En el plano tecnológico no pueden negarse evidentes avances, además de que hemos de poner en valor las decididas acciones del CGPJ para avanzar en la dotación de herramientas a los juzgados y tribunales que faciliten y economicen múltiples gestiones de las que han de realizarse en la tramitación de los procedimienrttos judiciales, contribuyendo a la agilización, eficacia y ahorro de tiempo en la resolución de los expedientes. En este sentido ha sido determinante el Punto Neutro Judicial y la aplicación Inter-lus ${ }^{21}$. Sin embargo, la falta de interoperabilidad entre los distintos sistemas de gestión procesal es el principal obstáculo para una Justicia plenamente electrónica al no haber cumplido el CGPJ el mandato contenido en el artículo 230 de la LOPJ de exigir su efectiva compatibilidad, tal y como establecía el apartado 5 del artículo en su anterior redacción, competencia que en la redacción actual el apartado 6 atribuye al Comité Técnico Estatal de la Administración de Justicia Electrónica (CTEAJE).
En este contexto no es posible trabajar con el expediente judicial electrónico y que este despliegue todas las funcionalidades y ventajas que de su implantación y utilización se pueden obtener y que se definen y regulan en la LUTICAJ. También en el plano tecnológico resulta determinante la incompatibilidad de varios de los sistemas de gestión procesal de algunas comunidades autónomas con la plataforma LexNET ${ }^{22}$. Más allá de que revertir esta situación resulta especialmente costoso tanto económica como técnicamente -hacer los sistemas compatibles requiere un volcado de documentación que precisa de fuertes inversiones de dinero y tiempo, además de superar otras complicaciones tecnológicas-, situación que podría haberse evitado si, desde el primer momento, el CGPJ hubiera autorizado solo sistemas compatibles que cumplieran los requerimientos técnicos determinados por el propio CGPJ. Dicha previsión por parte del órgano de gobierno de los jueces cobraba si cabe más sentido precisamente por la fragmentación competencial a que hemos aludido, pues podían presumirse las dificultades que se presentarían en el futuro para hacer compatibles los distintos SGP creados por las Aministraciones autonómicas con competencias en la materia, como efectivamente está sucediendo.

Finalmente, el diseño de mejoras en las herramientas que hagan más útil y facilite el uso para la gestión de los expedientes resulta fundamental cuando se trata de abandonar un modelo de trabajo para empezar a utilizar otro. El usuario o usuaria debe encontrar ventajas en el nuevo modelo para que no desarrolle resistencias e inercias contrarias a su uso. De la misma forma es preciso efectuar las inversiones necesarias para que las salas de vistas estén dotadas

19. Información obtenida de la página web del Ministerio de Justicia: https://www.mjusticia.gob.es/cs/Satellite/Portal/es/justicia-espana/ proyectos-transformacion/oficina-judicial/mapa-sedes-oficina-judicial [Fecha de consulta: 3 de septiembre de 2020].

20.Ibid.: https://www.mjusticia.gob.es/cs/Satellite/Portal/es/justicia-espana/proyectos-transformacion/oficina-fiscal\#id_1288784209469 [Fecha de consulta: 3 de septiembre de 2020].

21. Una detallada descripción de las utilidades del Punto Neutro Judicial y de la aplicación Inter-lus puede consultarse en DELGADO GARCÍA, A. Ma; OLIVER CUELLO, R. (2007). «Iniciativas recientes de la e-Justicia en España». IDP. Revista de Internet, Derecho y Política, núm. 4, págs. 24 y 25. Monográfico e-Justicia [en línea] https://idp.uoc.edu/42/volume/0/issue/4/ [Fecha de consulta: 3 de septiembre de 2020].

22. La fragmentación competencial vuelve a presentarse como un hecho diferencial del grado de implantación, siendo distinto en función de la comunidad autónoma de que se trate. En Navarra, País Vasco y Cantabria tanto la presentación de escritos como la recepción de notificaciones se hace a través de sus SGP (Navarra-Avatius; País Vasco-Justizia.Sip; y Cantabria-Vereda). En Cataluña, la presentación se hace con su sistema de gestión procesal (Justicia.Cat), pero las notificaciones sí se reciben por LexNET. En Aragón, excepto en Zaragoza, se utiliza Avantius para la recepción de notificaciones y la presentación de escritos está temporalmente fuera de servicio. Con respecto a la Fiscalía General del Estado, su SGP Fortuny ya es compatible con LexNET en la actualidad. Para un detallado estudio sobre la cuestión, CERNADA BADÍA, R. (2019). «LexNET o la selección natural en el foro del siglo xxı». En: GÓMEZ MANRESA, M. F.; FERNÁNDEZ SALMERÓN, M. (coords.). Modernización digital e innovación en la Admnistración de Justicia. Navarra: Aranzadi-Thomson Reuters (Cizur Menor), págs. 401 a 429 
de los equipos informáticos necesarios para poder realizar y seguir un juicio de modo totalmente electrónico.

Según se ha advertido con acierto, la situación actual deriva de una «falta de continuidad en las políticas integradas de gestión del cambio» ${ }^{23}$. Los objetivos establecidos en las normas reguladoras que no se han cumplido son relevantes, tal y como sucede con el relativo al «papel cero», de imposible cumplimiento en estos momentos ${ }^{24 ;}$ o la definitiva incorporación de los medios tecnológicos necesarios y adecuados para hacer de la Justicia un servicio público más cercano a la ciudadanía y más transparente ${ }^{25}$, permitiendo el acceso a los expedientes judiciales. De la misma forma el problema de la insuficiente dotación de órganos judiciales sigue sin resolverse ${ }^{26}$, así como la falta de eficacia y la dilación en la resolución de los procedimientos, que sigue siendo apreciado como otro grave y endémico problema ${ }^{27}$.

Ante esta situación el CGPJ ha aprobado la Instrucción $1 / 2018$, relativa a la obligatoriedad para jueces y magistrados del empleo de medios informáticos a que se refiere el artículo 230 de la Ley Orgánica 6/1985, de 1 de julio, del Poder Judicial, en la que establecen las condiciones y requerimientos técnicos que deben cumplir los medios tecnológicos al servicio de la Administración de Justicia para que su uso se pueda imponer como obligatorio a los jueces y magistrados, que analizamos seguidamente. La pregunta a plantear resulta elemental: la citada Instrucción, ¿ha servido para impulsar este proceso?

\section{La Instrucción 1/2018, del CGPJ: ¿un freno o un avance para la definitiva modernización tecnológica de la Administración de Justicia?}

A partir del 1 de enero de 2016, en aplicación de lo dispuesto en el artículo 230 de la LOPJ, la LEC obliga a todos los profesionales de la Justicia y órganos judiciales y fiscalías a la utilización de los sistemas telemáticos existentes en la Administración de Justicia para la presentación de escritos y documentos y la realización de actos de comunicación procesal, debiendo la Administración competente, las demás Administraciones, profesionales y organismos que agrupan a los colectivos establecer los medios necesarios para que ello sea una realidad. La obligatoriedad y exclusividad del uso de medios electrónicos y la prohibición de transcripción y empleo del papel en la tramitación de los procedimientos ${ }^{28}$ que impone el mencionado artículo 230 de la LOPJ y el 147 de la LEC conlleva la necesaria puesta a disposición de los jueces y magistrados de los

23. PARRA GARCÍA, J .L. (2019), op. cit., pág. 20. El autor identifica una serie de dificultades que han lastrado el proceso de modernización.

24. Véase CERDÁ MESEGUER. J. I. (2016). «El objetivo “papel cero" en la Administración de Justicia española: ¿una realidad procesalmente imposible?». En: BUENO DE MATA, F. (dir.). Hacia una Justicia 2.0. Salamanca: Actas del XX Congreso Iberoamericano de Derecho e Informática, vol. II, págs. 35-48.

25. CERRILLO I MARTÍNEZ, A. (2012). «La dotación suficiente de medios e instrumentos electrónicos y el marco general de la cooperación interadministrativa en materia de Administración de Justicia». En: GAMERO CASADO, E.; VALERO TORRIJOS, J. (coords). Las Tecnologías de la Información y la Comunicación en la Administración de Justicia. Análisis sistemático de la Ley 18/2011, de 5 de julio. Navarra: AranzadiThomson Reuters. También CERRILLO I MARTíNEZ, A. (2007). «E-justicia: las tecnologías de la información y el conocimiento al servicio de la Justicia Iberoamericana en el siglo XXI». IDP. Revista de Internet, Derecho y Política, núm. 4, pág. 5. Monográfico e-Justicia [en línea] https://idp.uoc.edu/42/volume/0/issue/4/ [Fecha de consulta: 3 de septiembre de 2020]. En este sentido véase también DELGADO GARCÍA, A. M.a; OLIVER CUELLO, R. (2006), op. cit., pág. 10.

26. Según el Cuadro de Indicadores de la Justicia en la UE de 2019, de la Comisión Europea, COM 2019, la media de jueces en España por cada cien mil habitantes es de doce, mientras que la media europea se sitúa en veintidós. El Eurobarómetro de la Justicia de la UE indica la mala imagen de la Justicia para los ciudadanos, de los cuales un 55\% no confía en la independencia judicial.

27. En este sentido, Mora-Sanguinetti, J. S.; Martínez-Matute, M. (2020). «Los impactos económicos del funcionamiento de la Justicia en la Región de Murcia». Murcia: Consejo Económico y Social de la Región de Murcia, febrero 2020. Se afirma que la lentitud en la resolución de las causas judiciales puede ser causa de la paralización de proyectos de inversión, o de una menor tasa de emprendimiento de nuevos negocios. Según sostiene el informe, un leve incremento del colapso judicial podría elevar los niveles de paro en la Región de Murcia al 20\% en un solo año [en línea] https://www.cesmurcia.es/cesmurcia/paginas/publicaciones/UltimasPublicaciones.seam?publd=2241 [Fecha de consulta: 3 de septiembre de 2020].

28. Salvo algunas excepciones como se advierte en CERDÁ MESEGUER, J. I. (2019). «Hacia una Administración de Justicia plenamente electrónica: disfunciones normativas y jurisprudenciales». En: GÓMEZ MANRESA, M. F.; FERNÁNDEZ SALMERÓN, M. (coords.). Modernización digital e innovación en la Administración de Justicia. Navarra: Aranzadi-Thomson Reuters (Cizur Menor), págs. 369 a 397. 
medios adecuados para poder desarrollar su trabajo con plenas garantías y sin que el mismo les suponga duplicar esfuerzos y trabajo. Ante tales obligaciones legales, la falta de la correlativa dotación de los medios tecnológicos necesarios y adecuados provocó una inercia contraria a asumir tales obligaciones por parte de los titulares de los órganos judiciales, quienes han constatado que la incabada transformación digital de la Administración de Justicia complica en muchas ocasiones su tarea y no ha contribuido a subsanar los problemas que intentaban afrontarse.

En este contexto se promulga la Instrucción 1/2018, cuya justificación queda expuesta en su Exposición de Motivos, donde se evidencia que el CGPJ, después de muchos y reiterados incumplimientos en la normativa general y específica en materia de implantación de las TIC en la Administración de Justicia, ha tomado la decisión de ejercer sus competencias de coordinación en la materia que le atribuyen tanto la LUTICAJ como la LOPJ ${ }^{29}$.

La Instrucción trae causa en las modificaciones que el artículo 230.1 y 2 de la LOPJ ha sufrido, y en cuya redacción actual se establece la obligatoriedad del uso por los jueces y tribunales de los «medios técnicos, electrónicos, informáticos y telemáticos, puestos a su disposición para el desarrollo de su actividad y el ejercicio de sus funciones». Ante tal previsión legal y la consecuencia jurídica derivada de un posible incumplimiento por parte de los jueces y magistrados, que podría llevar aparejadas sanciones disciplinarias por desatención e incumplimientos de los deberes del cargo, el CGPJ acuerda establecer los requisitos que deben satisfacer los medios técnicos para que la obligatoriedad de su uso sea exigible. Los motivos que sustentan tal decisión, más allá de ser absolutamente razonables, impiden que se traslade a jueces y magistrados la carga de soportar las consecuencias que se derivan de las decisiones de las Administraciones competentes en materia de Administración de Justicia. En concreto, en el sentido de que, de no ejercer ese control previo, se correría el riesgo de que, bajo la aparien- cia del suministro de medios técnicos -un simple programa informático de gestión procesal-, se alteren las condiciones del puesto de trabajo del juez o magistrado.

Conforme a lo dispuesto en el artículo 1 de la Instrucción, los ejes de actuación del CGPJ se centran en tres cuestiones relacionadas entre sí. En primer lugar, las especificaciones y requerimientos técnicos que deben reunir los programas y SGP para trabajar en un entorno de expediente judicial electrónico, tanto integrado en el SGP o externo al mismo, como herramienta especializada para trabajar con él, a lo cual dedica la norma el artículo 2, en el que se establecen los requisitos técnicos para que la obligatoriedad de su uso sea exigible a jueces y magistrados. En relación directa con este eje está el artículo cuarto de la norma, que regula el procedimiento para la verificación de que los programas reúnen las condiciones que permiten al CGPJ imponer su obligatoriedad para jueces y magistrados.

El segundo eje de actuación es el referido a la formación en la utilización de los programas ${ }^{30}$, artículo tercero de la norma, estableciéndose la obligatoriedad de que las Administraciones que implanten los programas de gestión procesal deberán facilitar a los jueces y magistrados la formación necesaria para el uso de los mismos. Dicha formación será validada por la Comisión Permanente del CGPJ antes de imponer a los jueces y tribunales la obligatoriedad de su uso, que ponderará si la misma es adecuada por tiempo, contenidos y calidad, previo informe del Servicio de Formación Continua y de la Sección de Informática Judicial. Se añade además que el uso de programas y SGP o de los instrumentos informáticos no será obligatorio mientras no se imparta la formación necesaria en los términos indicados. Asímismo, por primera vez se introduce por parte del CGPJ una nueva variable dirigida a las Administraciones con competencias en materia de Justicia consistente en el establecimiento de políticas de prevención de salud profesional con relación al uso de pantallas de visualización de datos conforme a la normativa del Plan de Prevención de Riesgos Laborales de la Carrera Judicial ${ }^{31}$.

29. MARTíNEZ GUTIÉRREZ, R. (2019). «Los retos de la innnovación tecnológica en la Jurisdicción Contencioso-Administrativa». Ponencia presentada en el XIV Congreso Nacional de Profesores de Derecho Administrativo, celebrado en Murcia, los días 8 y 9 de febrero de 2019 , pág. 20. Véase también MARTÍNEZ GUTIÉRREZ, R. (2019). «La e-Justicia contencioso-administrativa después de la Instrucción 1/2018 del CGPJ». Revista General de Derecho Administrativo, núm. 51.

30. Parte de las quejas y demandas formuladas por los colectivos de operadores judiciales implicados (jueces, fiscales, jueces, fiscales, letrados de la Administración de Justicia y funcionarios) han sido por la escasa formación recibida para el uso de programas y herramientas que se les imponía como obligatorios, por ejemplo LexNET. Véase CERDÁ MESEGUER, J. I. (2018), op. cit., págs. 270 a 277.

31. La Comisión Permanente del CGPJ aprobó el 27 de enero de 2015 el primer Plan de Prevención de Riesgos Laborales para la Carrera Judicial. Información obtenida de la web oficial del CGPJ. 
El tercer eje se concreta en las consecuencias derivadas de la no superación del test de requisitos técnicos, de gestión y de formación mínimos para que el programa pueda imponerse como obligatorio. Para estos casos, la Instrucción prevé que se deberá garantizar el acceso a los expedientes en papel, así como su conservación en dicho formato en tanto subsista la situación descrita.

La Instrucción incorpora un anexo técnico en el que se regulan especificaciones técnicas para el expediente judicial electrónico, que impone a las Administraciones Públicas con competencias en la materia que cualquier desarrollo de sistemas o herramientas deberá cumplir con las especificaciones señaladas por el CTEAJE.

\section{Conclusiones}

Conforme a lo expuesto, la valoración que hemos de hacer de las acciones desarrolladas por el CGPJ y de la Instrucción 1/2018 del CGPJ debe ser positiva, sin que en ningún caso pueda ser esta considerada un freno para la culminación de la modernización tecnológica de la Justicia $^{32}$. Aunque es la primera vez que el CGPJ está ejerciendo de forma decidida sus competencias en la materia a fin de aprobar que los SGP sean compatibles y superen las especificaciones técnicas mínimas, debe considerarse una iniciativa que ayuda a superar las dificultades sobre interoperabilidad, lo que conllevará que el uso de tecnologías comunes -LexNET, por ejemplo- pueda ser una realidad en todo el territorio nacional.
Por otra parte, asegura que jueces y magistrados de todo el país tengan acceso a una formación adecuada sobre los medios técnicos de que dispongan y deban utilizar obligatoriamente, lo cual puede suponer que se esté más cerca de conseguir el objetivo de la plena implantación del expediente judicial electrónico. Resulta también positiva porque resuelve, sin invadir competencias del resto de Administraciones implicadas, los problemas que podrían derivarse en el futuro respecto a cambios en los SGP o en los programas por parte de estas, pues tendrán que ser previamente aprobados por el propio CGPJ, lo que implica mayor garantía para jueces y magistrados, a quienes solo podrá imponerse su uso después de superar ese control previo.

Se puede concluir que el CGPJ ha adoptado una actitud proactiva en el plano tecnológico. Esta debe ser acompañada de otras acciones coordinadas, que corresponde efectuar a las otras Administraciones competentes, con la finalidad de subsanar el problema de la falta de jueces y magistrados; de realizar las inversiones precisas para dotar de medios humanos, materiales y espaciales a la Administración de Justicia; y de culminar definitivamente la implantación de la NOJ y del expediente judicial electrónico. De esta forma se estará en condiciones de empezar a revertir la situación actual de la Administración de Justicia, de corregir sus defectos y de subsanar sus deficiencias.

32. No obstante, es llamativa la falta de preocupación del CGPJ por las implicaciones que tiene este proceso desde la perspectiva de la protección de datos, sobre todo a la vista de las importantes novedades que plantea la nueva regulación europea. Acerca de la importancia de este requerimiento, en particular por lo que respecta al expediente judicial, véase ARENAS RAMIRO, M. (2019). «La modernización de la tutela judicial efectiva y el expediente judicial electrónico». En: GÓMEZ MANRESA, M. F.; FERNÁNDEZ SALMERÓN, M. (coords.). Modernización digital e innovación en la Admnistración de Justicia. Navarra: Aranzadi-Thomson Reuters (Cizur Menor), págs. 285 y 286. 


\section{Referencias bibliográficas}

ARENAS RAMIRO, M. (2019). «La modernización de la tutela judicial efectiva y el expediente judicial electrónico». En: GÓMEZ MANRESA, M. F.; FERNÁNDEZ SALMERÓN, M. (coords.). Modernización digital e innovación en la Administración de Justicia. Navarra: Thomson Reuters Aranzadi (Cizur Menor).

ARNAIZ SERRANO, A.; TOMÁS PORTER, J. J. (2010). «La nueva oficina judicial y el nuevo modelo procesal: un estudio sobre la organización y funciones en la oficina judicial y los procesos judiciales tras la reforma de la legislación procesal operada por la Ley 13/2009». Revista jurídica de la Comunidad Valenciana: jurisprudencia seleccionada de la Comunidad Valenciana, núm. 33.

BUENO DE MATA, F. (2014). Prueba electrónica y Proceso 2.0. Valencia: Tirant Lo Blanch.

CLÈRIES I NERÍN, N. (2007). «Administración electrónica en el Área de Justicia». IDP. Revista de Internet, Derecho y Política, núm. 4. Monográfico e-Justicia [en línea] https://idp.uoc.edu/42/volume/0/ issue/4/ [Fecha de consulta: 3 de septiembre de 2020].

CERDÁ MESEGUER. J. I. (2016). «El objetivo "papel cero" en la Administración de Justicia española: ¿una realidad procesalmente imposible?». En: BUENO DE MATA, F. (dir.). Hacia una Justicia 2.0. Salamanca: Actas deI XX Congreso Iberoamericano de Derecho e Informática, vol. II, págs. 35-48.

CERDÁ MESEGUER, J. I. (2018). El uso de medios electrónicos en la Administración de Justicia. Del expediente en papel al expediente electrónico. Valencia: Tirant Lo Blanch.

CERDÁ MESEGUER, J. I. (2019). «Hacia una Administración de Justicia plenamente electrónica: disfunciones normativas y jurisprudenciales». En: GÓMEZ MANRESA, M. F.; FERNÁNDEZ SALMERÓN, M. (coords.). Modernización digital e innovación en la Admnistración de Justicia. Navarra: AranzadiThomson Reuters (Cizur Menor).

CERNADA BADÍA, R. (2019). «LexNET o la selección natural en el foro del siglo xxi». En: GÓMEZ MANRESA, M. F.; FERNÁNDEZ SALMERÓN, M. (coords.). Modernización digital e innovación en la Admnistración de Justicia (Navarra): Aranzadi-Thomson Reuters (Cizur Menor).

CERRILLO I MARTíNEZ, A. (2007). «E-justicia: las tecnologías de la información y el conocimiento al servicio de la Justicia Iberoamericana en el siglo xxI》. IDP. Revista de Internet, Derecho y Política, núm. 4. Monográfico e-Justicia [en línea] https://idp.uoc.edu/42/volume/0/issue/4/ [Fecha de consulta: 3 de septiembre de 2020].

CERRILLO I MARTÍNEZ, A. (2010). «Cooperación entre Administraciones públicas para el impulso de la administración electrónica». En: GAMERO CASADO, E.; VALERO TORRIJOS, J. La Ley de Administración Electrónica. Comentarios a la Ley 11/2007, de 22 de junio, de Acceso Electrónico de los Ciudadanos a los Servicios Públicos. Navarra: Aranzadi-Thomson Reuters (Cizur Menor).

CERRILLO I MARTÍNEZ, A. (2012). «La dotación suficiente de medios e instrumentos electrónicos y el marco general de la cooperación interadministrativa en materia de Administración de Justicia». En: GAMERO CASADO, E.; VALERO TORRIJOS, J. (coords.). Las tecnologías de la información y la comunicación en la Administración de Justicia. Análisis sistemático de la Ley 18/2011, de 5 de julio. Navarra: Aranzadi-Thomson Reuters.

DELGADO GARCÍA, A. M.a; OLIVER CUELLO, R. (2006). Las tecnologías de la información y la comunicación en la Administración de Justicia. Oñati (Bilbao): Instituto Vasco de Administración Pública.

DELGADO GARCÍA, A. M.a; OLIVER CUELLO, R. (2007). «Administración de Justicia y tecnologías de la información y la comunicación: aspectos jurídicos». Revista Aranzadi de Derecho y Nuevas Tecnologías, núm. 13. 
DELGADO GARCÍA, A. M.a; OLIVER CUELLO, R. (2007). «Iniciativas recientes de la e-Justicia en España». IDP. Revista de Internet, Derecho y Política, núm. 4. Monográfico e-Justicia [en línea] https:// idp.uoc.edu/42/volume/0/issue/4/ [Fecha de consulta: 3 de septiembre de 2020].

GAMERO CASADO, E.; MARTíNEZ GUTIÉRREZ, R. (2010). «El Derecho Administrativo ante la Era de la Información». En: GAMERO CASADO, E.; VALERO TORRIJOS, J. (coords.). La Ley de Administración Electrónica. Comentario sistemático a la Ley 11/2007, de 22 de junio, de Acceso Electrónico de los Ciudadanos a los Servicios Públicos. Navarra: Aranzadi-Thomson Reuters.

JIMÉNEZ ASENSIO, R. (2010). «El encaje constitucional de la NOJ». Ponencia presentada en el curso «La Nueva Oficina Judicial». Madrid: CENDOJ.

JIMÉNEZ GÓMEZ, C. E. (2014). «Desafíos de la modernización de la Justicia en tiempos del Gobierno Abierto». Revista Digital de Derecho Administrativo, núm. 12.

MARTíNEZ GUTIÉRREZ, R. (2019). «Los retos de la innnovación tecnológica en la Jurisdicción Contencioso-Administrativa». Ponencia presentada en el XIV Congreso Nacional de Profesores de Derecho Administrativo, celebrado en Murcia, los días 8 y 9 de febrero de 2019.

MARTíNEZ GUTIÉRREZ, R. (2019). «La e-Justicia contecioso-administrativa después de la Instrucción 1/2018 del CGPJ». Revista General de Derecho Administrativo, núm. 51.

MORA-SANGUINETTI, J. S.; MARTíNEZ-MATUTE, M. (2020). «Los impactos económicos del funcionamiento de la Justicia en la Región de Murcia». Murcia: Consejo Económico y Social de la Región de Murcia, febrero de 2020. [en línea] https://www.cesmurcia.es/cesmurcia/paginas/publicaciones/ UltimasPublicaciones.seam?publd=2241 [Fecha de consulta: 3 de septiembre de 2020].

ORTUÑO MUÑOZ, P. (2011). «Del arancel al expediente electrónico (Notas históricas sobre el modelo de oficina judicial español)». Revista Jurídica Fundación Mariano Ruiz-Funes, núm. 45.

PARRA GARCÍA, J. L.; PASQUAL DEL RIQUELME HERRERO, M. (2009). «Oficina Judicial integrada o hacia una Justicia inteligente en España». Boletín del Ministerio de Justicia, año 63, núm. 2.094.

PARRA GARCÍA, J. L. (2010). «El año uno en la Oficina Judicial: nueva organización, nuevas formas de hacer Justicia». Derecho y Jueces, EL DERECHO, núm. 55.

PARRA GARCÍA, J. L. (2019). «La Oficina Judicial en España: un balance de diez años». Actividad for-

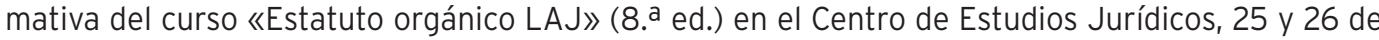
noviembre de 2019.

SEOANE CHACARRÓN, J. (2011). «El Secretario Judicial ante la Ley 13/2009, de 3 de noviembre, de Reforma de la Legislación Procesal (civil y penal) para la implantación de la Nueva Oficina Judicial». Diario La Ley, núm. 7.561.

SUÁREZ-QUIÑONES Y FERNÁNDEZ, J. C. (2010). «Administración de Justicia y Nuevas Tecnologías: presente y futuro». Diario La Ley, núm. 7.421.

VALERO TORRIJOS, J. (2013). Derecho, innovación y Administración electrónica. Sevilla: Derecho Global. 


\title{
Cita recomendada
}

CERDÁ MESEGUER, Juan Ignacio (2020). «La modernización y transformación digital de la Administración de Justicia: el papel del Consejo General del Poder Judicial». IDP. Revista de Internet, Derecho y Política,núm. 31, págs. 1-12. UOC [Fecha de consulta: dd/mm/aa]. http://dx.doi.org/10.7238/idp.v0i31.3239

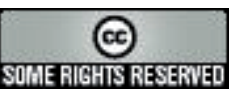

\begin{abstract}
Los textos publicados en esta revista están -si no se indica lo contrario- bajo una licencia Reconocimiento-Sin obras derivadas 3.0 España de Creative Commons. Puede copiarlos, distribuirlos y comunicarlos públicamente siempre que cite su autor y la revista y la institución que los publica (IDP. Revista de Internet, Derecho y Política; UOC); no haga con ellos obras derivadas. La licencia completa se puede consultar en: http://creativecommons.org/ licenses/by-nd/3.0/es/deed.es.
\end{abstract}

\section{Sobre la autor}

Juan Ignacio Cerdá Meseguer

jignaciocm@um.es

Universidad de Murcia

Licenciado en Derecho y doctor por la Universidad de Murcia con la tesis El expediente judicial electrónico, ha participado como ponente y comunicante en diversos congresos nacionales e internacionales y es autor de una monografía y varias publicaciones en obras colectivas y revistas especializadas. Sus líneas de investigación se han centrado principalmente en las implicaciones jurídicas del uso de medios electrónicos en la Administración de Justicia y en el marco normativo de la protección de los datos de carácter personal. Abogado en ejercicio con despacho propio durante veintisiete años, actividad profesional compaginada con la docencia universitaria, actualmente es profesor del Departamento de Derecho Administrativo e investigador en iDerTec a tiempo completo, participando en varios proyectos de investigación sobre dichos temas. 